\title{
EVALUATION OF A DIGITAL INTERFACE THAT INTEGRATES USER DIVERSITY TO AWARE INDIVIDUALS ABOUT ENERGY
}

\author{
Ane Irizar-Arrieta ${ }^{1}$, Diego Casado-Mansilla ${ }^{1}$ and Aiur Retegi ${ }^{2}$ \\ ${ }^{I}$ DeustoTech, University of Deusto. Avenida de las Universidades, 24, 48007, Bilbao, Spain \\ ${ }^{2}$ Deusto Design Research Group, University of Deusto. Avenida de las Universidades, 24, 48007, Bilbao, \\ Spain
}

\begin{abstract}
Human factors play a key role on the improvement of energy efficiency at the workplace. Hence, they should be taken into account. Literature on Human-Computer Interaction (HCI) has demonstrated that 'one-size-fits-all' solutions fail addressing the user diversity in office environments. Therefore, this paper exposes how User Centered Design (UCD) and User Experience (UX) can act as pivotal tools to enhance user engagement in digital interfaces that promote sustainable behaviour at work. To accomplish this goal, a digital interface that offers a range of strategies and functions directed to different user archetypes has been designed and evaluated both quantitatively and qualitatively. Analysed data revealed the importance of the UX to design positive interactions which is a predictor of future system usage and engagement. The diversity of users and the impact of UCD on the Design for Sustainable Behaviour are discussed. Besides, future iterations of the design of a digital system that adapts dynamically to user profiles are proposed.
\end{abstract}

\section{KEYWORDS}

User Centered Design, User Experience, Sustainability, Interface Design, Interaction Design, Design for Sustainable Behaviour.

\section{INTRODUCTION}

Energy waste is a major world issue that implies designing new strategies to promote sustainability initiatives. Special attention should be given to the whole lifecycle of electronic devices and towards increasing the awareness of citizens to reduce energy consumption when using these devices. To maximise the latter initiative, a User-Centered perspective can be applied; overall taking into account that human factors play an important role in energy consumption (Hekler et al., 2013). This paper understands User Experience as a concept that 
embraces all aspects of users' interaction with a product, service and company. Moreover, some scholars consider that satisfactory UX improves the perception of the system and can be considered an indicator of a better uptake of the pro-environmental message (Law et al., 2009).

User Centered Design (UCD) includes a variety of research methods that involve the users from the beginning to the end of the process, offering a wide range of design tools that aims to understand their needs. Furthermore, UCD is related to the importance to all relative aspects about the understanding of the users (i.e. their diversity or their motivations) (Abras et al., 2004). UCD has been applied to inform design in different areas ranging from healthcare (Sax et al., 2007) to software development (Vredenburg et al., 2002). However, to the best of our knowledge, the relationship among UX, UCD methodology and energy efficiency has attracted little attention so far. Therefore, this paper presents the application of such methods to increase the awareness of workers about the energy consumption in their office environment.

We propose that, addressing the diversity of users in the design of a digital interface, positive feelings derived from the UX may encourage people towards augmenting energy awareness.

To shed light on this matter, our main contribution puts the focus on user diversity through the development and evaluation of a digital interface to promote energy consumption awareness with an improved UX for every user archetype. Our proposed design process evaluates the impact of UCD on the users and seeks to understand the possibilities of UX as a design attribute to raise awareness regarding sustainability. The paper is structured as follows: Section 2 provides a short background on interface design for sustainable behaviour. Section 3 describes the research, the design process and evaluation of the proposal. Section 4 details the main findings and the discussion, and Section 5 closes the paper with conclusions and future work.

\section{BACKGROUND}

The analysis of the State-of-art was undertaken systematically to understand the conceptual implications that should be taken into account in order to develop successful systems based on UCD principles.

Firstly, we reviewed existing literature about Design for Sustainable Behaviour (DfSB, a set of design techniques developed to affect users' behaviour) (Lockton et al., 2008). Next, focused on the UCD approach. Besides, the diversity of the user (i.e. user profiles) was reviewed in order to understand the different approaches that could be followed to offer personalised strategies to increase energy awareness.

\subsection{Design for Sustainable Behaviour}

Hekler et al. (2013) identified three broad uses of behavioural theories from HCI scholars: 1) to inform the design of technical systems; 2) to guide evaluation strategies; 3 ) to define target users or screen participants for evaluation studies. Hence, the author brought up the need for designers to understand the behavior change models developed by social scientists and use them to better generate effective design strategies. DfSB and behaviour change have 
been extensively studied in literature. Overall in the design community (Lockton et al., 2008) and in the Human Computer Interaction (Wever et al., 2008) to address the strategies on designing behaviour change products (in the design field), and to improve the interactions of the users when developing digital systems addressed to promote behaviour change.

\subsection{User-Centered Approach and User Diversity}

The User-Centered research puts the focus on the knowledge extracted from users. In addition, it assumes the diversity of people within its core activity. Thus, the analysis of different target users and user types is one of the first steps to develop useful interactive systems. The importance of understanding user diversity has been already explored in literature (Coskun \& Erbug, 2016). Different authors assume different dimensions of user diversity based on theoretical models or well-defined methodologies (Coskun et al., 2014; He et al., 2010; Halko \& Kientz, 2010; Kaptein et al., 2008; Lockton et al., 2012). Therefore, we can find different characterisations depending of the lens of each researcher. However, due to the lack of consensus about how to deal with diversity, we cannot consider any of them as golden standard to inform the classification of multi-users. Our design proposal has been implemented with features extracted from highlighted related work. The mix of strategies proposed by Yun et al. (2017) helps to reach different target users and complement each other. One of our contributions is the addition of control features to our digital interface, enabling the possibility of remotely managing energy-consuming devices and appliances. Finally, UX as a design strategy to promote the acceptance towards the interface and the provided message has been applied.

\subsection{Digital Interfaces for Sustainable Behaviour Change}

Narrowing the lenses on the HCI for sustainability, we reviewed related work of digital interface design. Although we can assume that the following works were developed with the users in mind, there is no explicit evidence of the usage of UCD methodologies. The literature offers a wide range of related work about digital interfaces for sustainable behaviour change. For this paper two works in this area are highlighted taking into account the relation with the user diversity and the strategies selected to foster the behaviour change: 1) Kilowh.at, a web based application developed to increase energy awareness through comparisons (Hedin \& Zapico, 2017). 2) Another web-based application directed to office workers that offers persuasive techniques like online feedback self-monitoring, advices, comparison and control functions to promote the sustainability at the workplace (Yun et al., 2017).

\section{SYSTEM DESIGN}

Taking into account the theoretical background related to DfSB, we developed an interface based on the UCD methodology. The proposed interface is an early design to test the correlation among UX, user diversity and pro-environmental awareness. The steps followed in the design process are: 1) initial research with users, 2) first Lo-Fi prototype, 3) heuristic evaluation of the first prototype, 4) Hi-Fi prototype design to be tested in the evaluation phase (explained at Section 4). These steps are further explained below. 


\subsection{Early Research with Users}

In the initial phase, we carried out user research with the aim of understanding potential users' insights to extract design requirements. We ran 2 Focus Group (Kitzinger, 1995) with 6 office employees in each one. The goals were 1) to discover the latent needs of the users regarding energy efficiency field (e.g. to comprehend which devices are the most used and when) and 2) to identify issues related with energy consumption and 3) to know the users as better as possible in the workplace. In the session, we asked to the participants to build their workday through pictograms and photos that showed work spaces and devices which would be potentially located in these areas (i.e. card sorting methodology (Wood, JR; Wood, LE; 2008)). After completing this task, we introduced a set of open topics to encourage the discussion about sustainability issues and energy efficiency at workplace. Figure 1 shows the reconstruction of the workday done by a pair of users during one of the session. Firstly, we found first that users hold forth comparative metrics to understand their energy consumption. In addition, we discovered that simple and easy visual metaphors were preferred as a means to visualize information in an effective and fast way. Besides, positive reinforcement was more likely to be accepted than the negative one. Another insight extracted from the session was that automated processes designed to improve energy efficiency should be complemented with manual control systems and that the information about systems and processes status must be shown to the users. The hybrid approach between automation and manual control was the most liked one by the users. This latter finding is in line with Casado-Mansilla's work (2016). The author found that a complete automation of the systems in favour of energy efficiency might spark a rebound effect on individual causing generalised distrust on technology. Thus, preventing users from controlling devices and appliances was associated with a reduction of the participant's confidence in technology as a means to solve all current environmental problems.

Having obtained the initial insights, we developed Personas (Harley, 2015) and Scenarios (Aoyama, 2007) to visualize and understand the potential archetypes of users. Our Personas were implemented with attributes extracted from the user research and from the mix made from literature: attributes based on the behaviour types (Lockton et al,. 2012) and based on the values and beliefs of the user (Petkov et al., 2011).

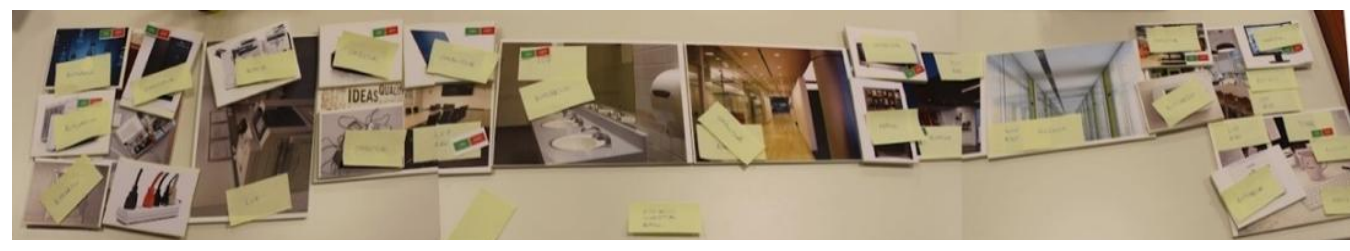

Figure 1. One of the work day reconstruction done at the Focus Group ordered as a timeline of the working day

\subsection{Low-Fi Prototype}

Because the use-context of the digital interface is the workplace, we decided to develop a web-based application to be consulted easily through a desktop computer. The Lo-Fi prototype 
IADIS International Journal on Computer Science and Information Systems

of the system was developed with Balsamiq Mockups ${ }^{1}$ in two phases. Firstly, the main system requirements were reviewed to define the functions of the interface. Secondly, the focus was put on user diversity with the application of Lockton (2012) (Pinball, Shortcut and Thoughtful) and Petkov's (2012) (Egoistic, Altruistic, Biospheric and social influenced) theories. The relationship between the user characterisation, and the strategies or features defined for each user type are presented in Table 1.

Table 1. Relation between user characterisation and the features developed on the interface.

\begin{tabular}{|c|c|c|c|}
\hline User Profile & Authors & Definition & Feature \\
\hline Pinball & Lockton et al. (2012) & $\begin{array}{l}\text { Linear models of } \\
\text { behaviour }\end{array}$ & $\begin{array}{l}\text { Usability, plain language, automation } \\
\text { options }\end{array}$ \\
\hline Shortcut & Lockton et al. (2012) & $\begin{array}{l}\text { Self-regulating } \\
\text { models of behaviour }\end{array}$ & $\begin{array}{l}\text { Comparisons between peers, public } \\
\text { ranking, goals }\end{array}$ \\
\hline Thoughtful & Lockton et al. (2012) & $\begin{array}{l}\text { Learning models of } \\
\text { behaviour }\end{array}$ & $\begin{array}{l}\text { Information about energy } \\
\text { consumption, tips, suggestions }\end{array}$ \\
\hline Egoistic & Petkov et al. (2012) & $\begin{array}{l}\text { Users with egoistic } \\
\text { values }\end{array}$ & Information about the money savings \\
\hline Altruistic & Petkov et al. (2012) & $\begin{array}{l}\text { Users with altruistic } \\
\text { values }\end{array}$ & $\begin{array}{l}\text { Information about long term impact of } \\
\text { the energy waste }\end{array}$ \\
\hline Biospheric & Petkov et al. (2012) & $\begin{array}{l}\text { Users with values } \\
\text { related to ecosystem }\end{array}$ & $\begin{array}{l}\text { Information about the impact on the } \\
\text { animals and plants }\end{array}$ \\
\hline $\begin{array}{l}\text { Social } \\
\text { influenced }\end{array}$ & Petkov et al. (2012) & $\begin{array}{l}\text { Users influenced by } \\
\text { peers }\end{array}$ & $\begin{array}{l}\text { Comparisons between peers, public } \\
\text { ranking, goals. }\end{array}$ \\
\hline
\end{tabular}

At the Lo-Fi prototype (Figure 2) the objective was to set up the Information Architecture of the interface and define the main elements and their placement and structure on the interface. In this first approach, all the elements of this prototype were provisional in order to be tested and validated through evaluation or inspection methods.
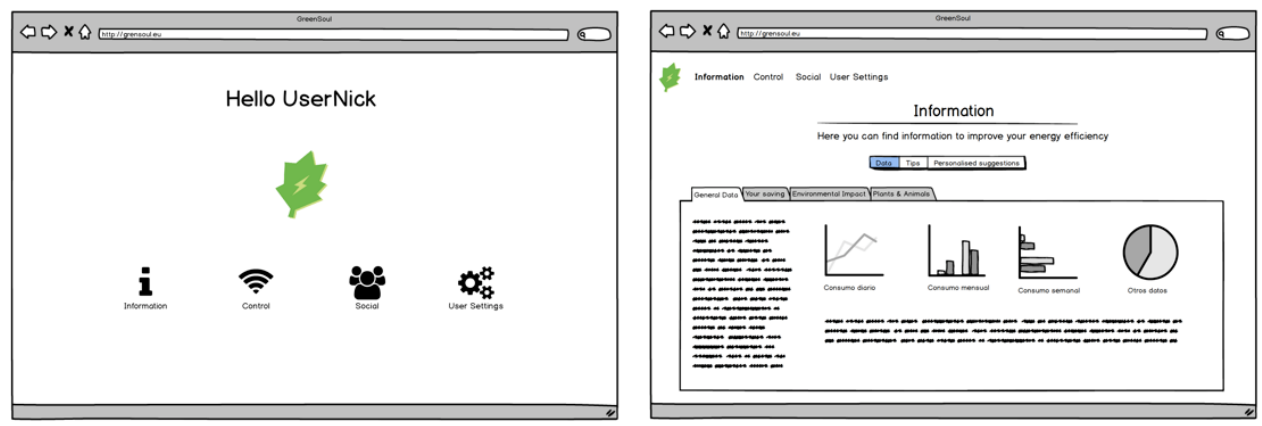

Figure 2. First sketches made for the web app with Balsamiq Mockup Software

\footnotetext{
${ }^{1}$ Website of the tool used to design the first Lo-Fi prototype: https://balsamiq.com
} 


\subsection{Heuristic Evaluation}

Following the UCD methodology, an initial evaluation should be made before iterating further. For that purpose we developed a Heuristic Evaluation (Nielsen, 1994), in order to find usability errors, design problems and non-well defined aspects. We found 10 errors according to Nielsen's methodology for refinement. Among them, four were not serious, five serious and one critic error. The most important errors were related to the website's navigation, correct understanding of the text tags and the coherence between the elements of the system and the information provided. Once the preliminary evaluation was finalised the next step was to iterate over the first refined version, developing a second prototype with more detailed elements and content and implementing the improvements extracted from the Heuristic Evaluation.

\subsection{High-Fi Prototype}

In this first iteration over the Lo-Fi Prototype, the main objective was to create a new prototype in a more detailed way. This is an essential phase to achieve a concrete idea of the future development of the system and to understand which are the most important features of it. The features implemented on this $\mathrm{Hi}-\mathrm{Fi}$ prototype are the ones that are going to be most used by the users. Besides, another objective of the prototype development is to design the main processes and features of the interface in order to evaluate them with real users and understand their opinions and insights about the proposed system.

The Hi-Fi prototype was developed with Axure $\mathrm{RP}^{2}$ software and resulted on a desktop web application with all the final elements defined but with limited functionalities. The prototype is available at AxureShare ${ }^{3}$. As can be seen in the Home Page (Figure 3), the interface contains four sections. These are: Information, Control, Social and User-Settings.

The first section, "Information", offers information related to energy efficiency through different metrics. Besides, it provides content to address user diversity with personalised strategies. The "Information" section has three subsections 1) "Data": it provides concrete information on energy expenditure through different approaches. 2) "Suggestions": it ideas and tips to be more efficient through the information shown in the monitoring of the devices. 3) "More Information": it shows other related complementary information such as articles, tips and other advices.

The "Data" section is divided another three tabs, addressing the user characterization proposed by Petkov et al. (2012). Firstly, information about energy expenditure is displayed, highlighting money savings. Besides, the application offers information about the environmental impact of the energy waste. Finally, the system shows information about impact of the energy waste on animals and plants (Figure 4). This latter content is mainly directed to the individuals with values related to the biosphere. All the content of the subsections, although they are directed to a certain profile, can act as a reinforcement for other user characterizations, enhancing the awareness of the sustainability with the reinforcement that offers the secondary and complementary information.

\footnotetext{
${ }^{2}$ The website of Axure RP software: https://www.axure.com/

${ }^{3}$ The Hi-Fi prototype can be visited here: http://wsobk2.axshare.com/ - c=2
} 
IADIS International Journal on Computer Science and Information Systems

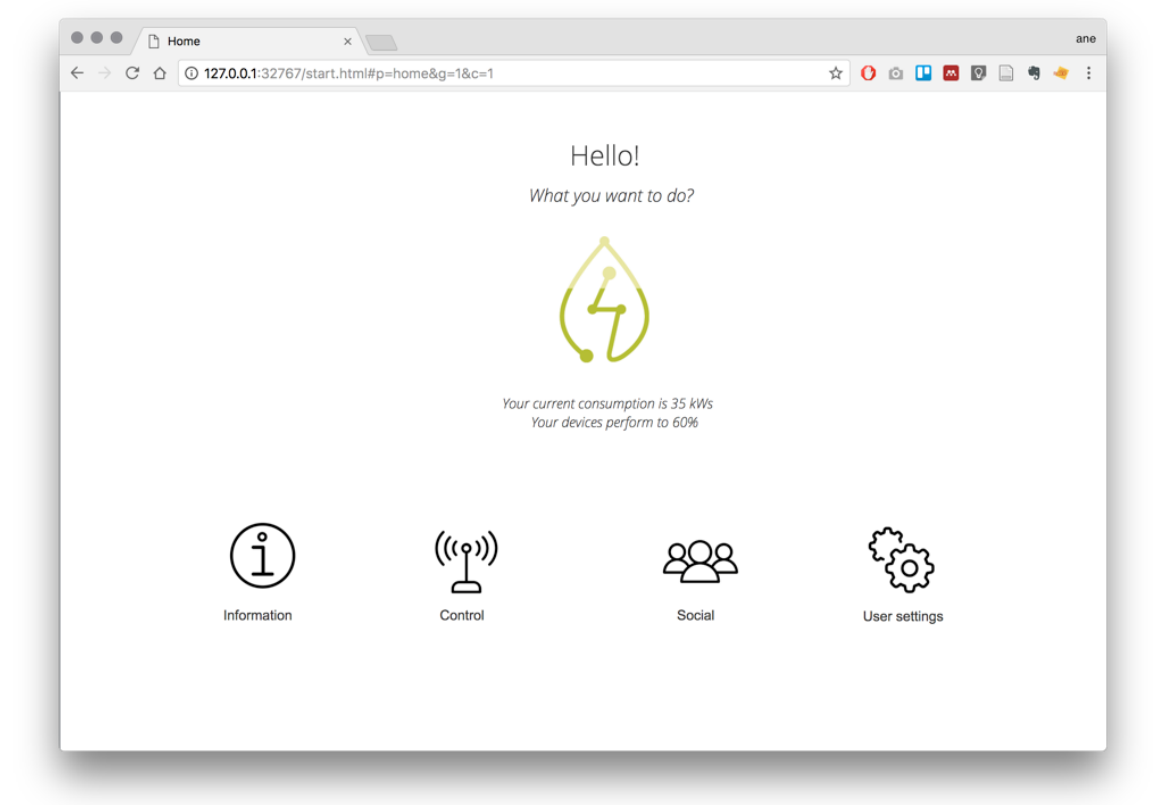

Figure 3. The "Home" page shows the average of the energy consumption of the worker's connected devices through colour and shape coding in the logo of the website which resembles to a tree leaf

The "Suggestions" and "More Information" pages offer more complementary content to improve the UX of the systems. With personalised suggestions, the aim is to involve the user providing useful information to improve their everyday life. The content provided in "More Information" page is addressed to the most interested individuals, and offers additional information about energy efficiency, like articles and videos.

The "Control" page is intended for remote control of each user's appliances. Here, the devices linked to the system are shown (e.g. the power strip plug that can be observed in Figure 5). "Add Device" allows linking new devices. Some of the features that can be managed in this page are the power on and off of the device remotely and the programming of when the device will be on or off. "Social" section (Figure 6) is intended to persuade a type of user whose values are closely related to the social influence, according to the defined strategy at the first conceptual design phase. This section offers the possibility to interact with other people, add groups of friends and make comparisons with other peers. The "Social" section also contains a sub-section relative to "Friends" (where the users can interact with others), another one to provide social comparison as persuasive reinforcement ("Me vs Others") and finally, one subsection where users are able to track the goals and achievements regarding their energy performance ("Goals"). The "Social" page offers dynamic content and navigation, and allows to explore the social side of environmental sustainability with the aim of creating networks of users to reinforce the behaviour change and awareness of individuals through social influence. To promote the involvement of the user, we propose a ranking, energy-related goals to achieve and comparisons between users. 


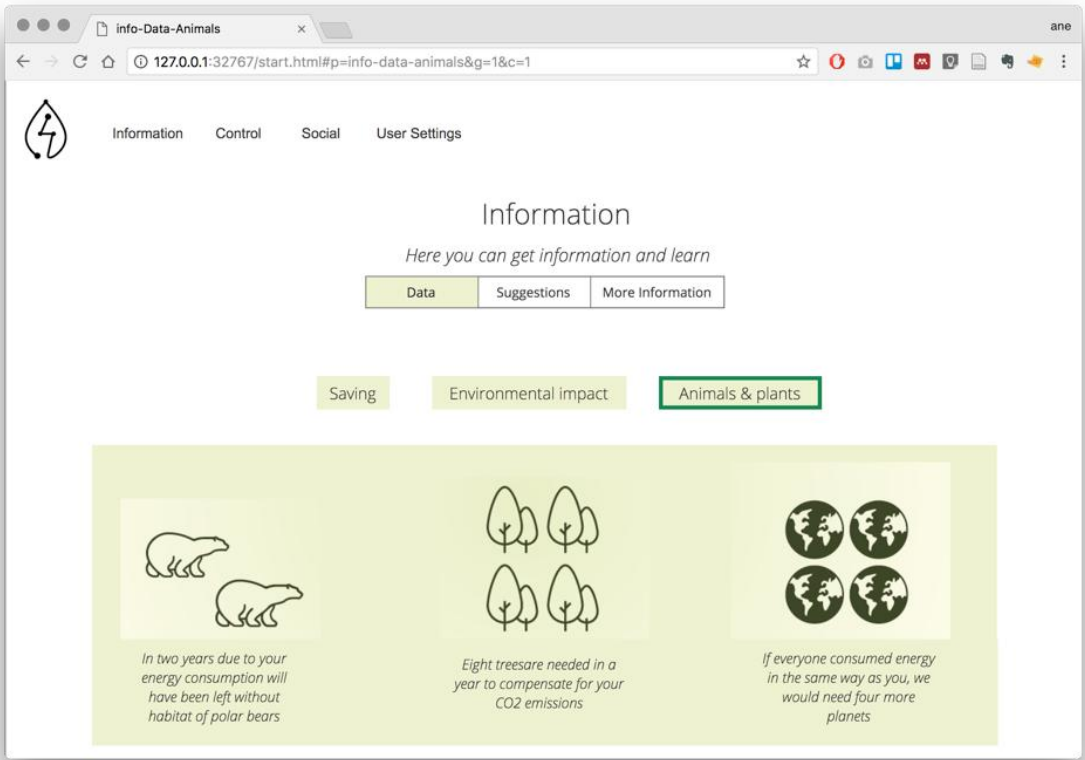

Figure 4. The "Information" section offers data to different users. In the picture above appears the information addressed to the users with values related to animals and plants

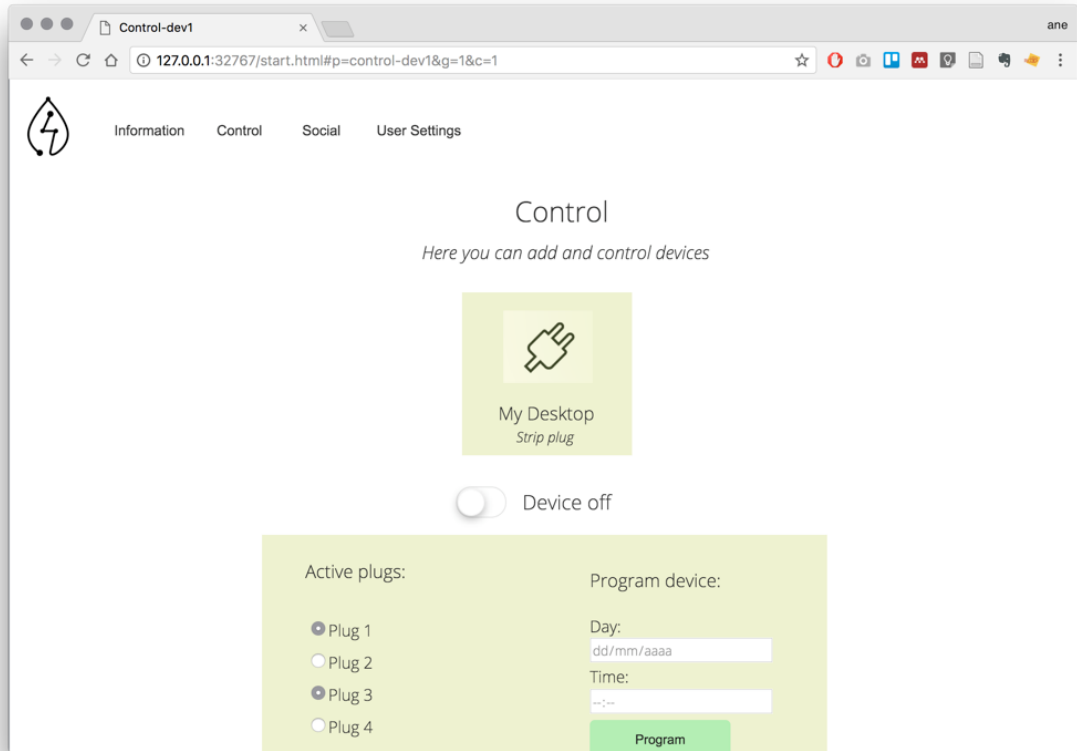

Figure 5. The picture shows the screen addressed to edit the features of the strip plug 
IADIS International Journal on Computer Science and Information Systems

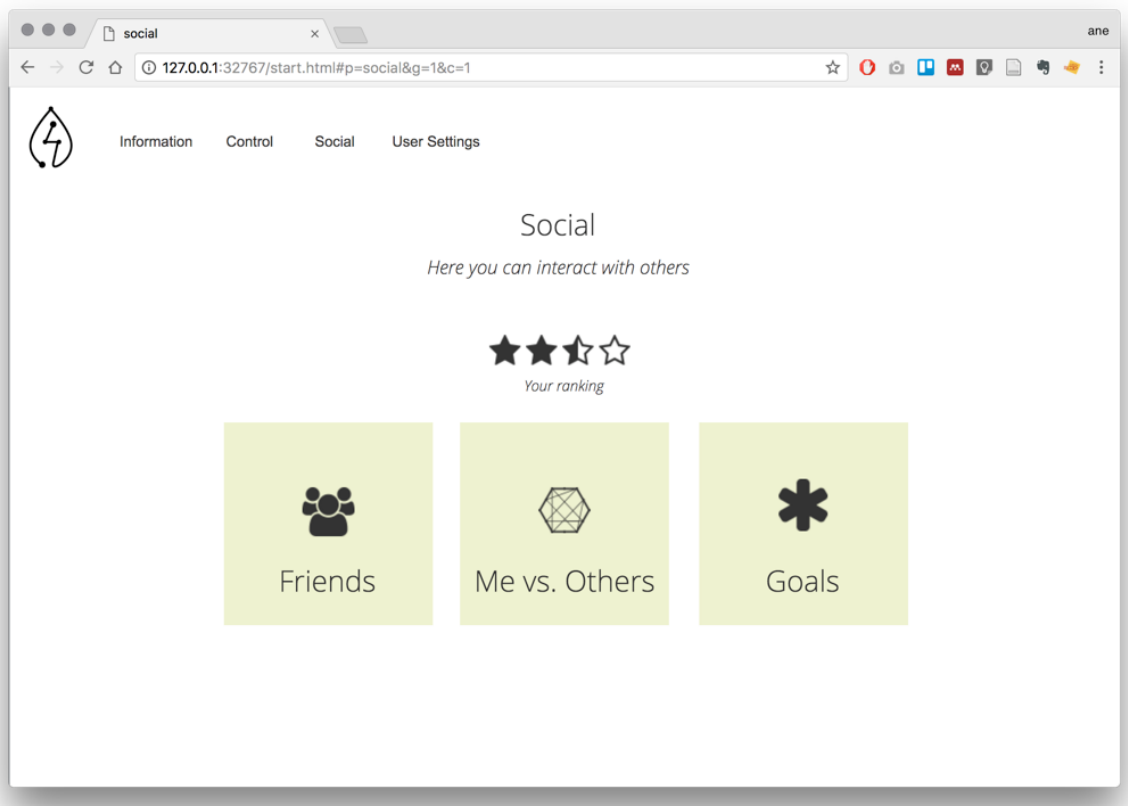

Figure 6. The "Social" screen shows the three different subsections

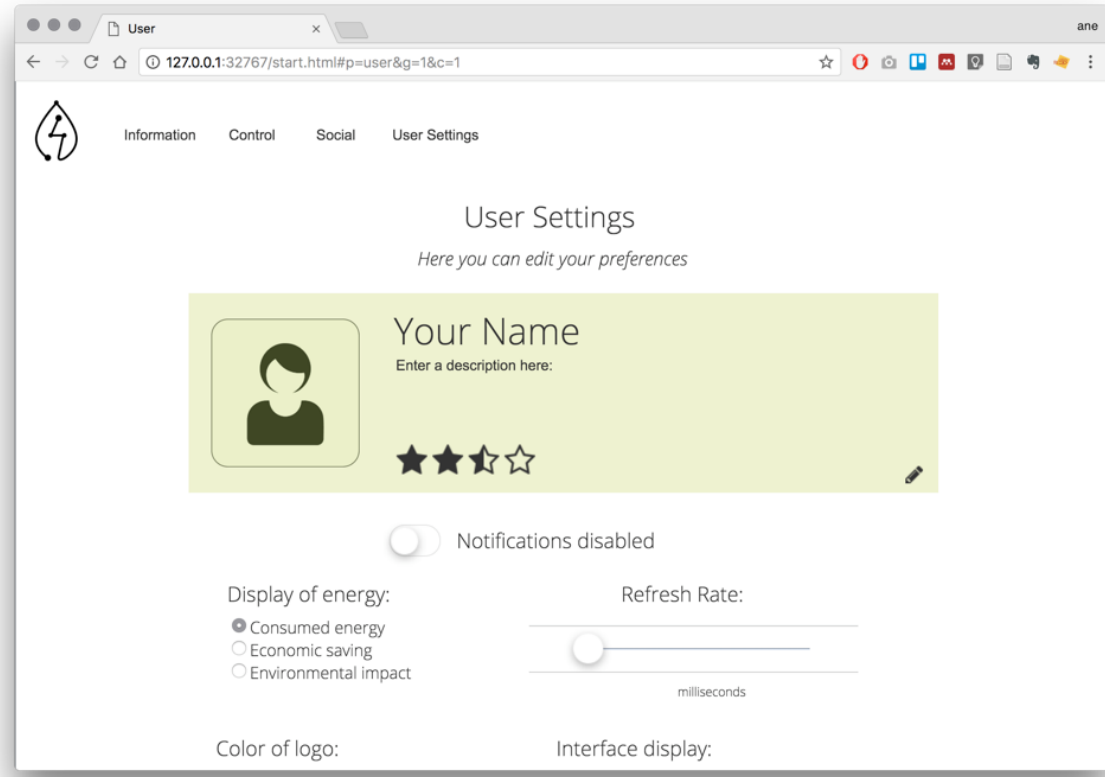

Figure 7. The "User Settings" section offers features addressed to personalise the interface 
The last section of the website is "User Settings" (Figure 7). It aims to improve the UX through the customization of some elements and functions. The customizable features of this part of the site are mainly addressed to edit the user's profile, but some settings are also included to change the measures of the visualization of the homepage, to change the refresh rate of the data, the colour of the logo to cite some among others.

\section{EVALUATION}

The evaluation with users at early stages of the design process is helpful to validate the decisions and to focus the design in the correct way before to prevent inconsistencies. The main objective of this first evaluation of the Hi-Fi prototype was to get the opinion of the users about the system and to know if it offers appropriate UX. We obtain feedback through usability test (Corry et al., 1997) and a semi-structured interview (Whiting, 2008). Furthermore, we handed out the System Usability Scale (SUS) questionnaire (Brooke, 1996) to the people recruited for the evaluation. The goal was to triangulate the evaluation through different methodologies to increase the reliability of the results according to Mackay \& Fayard (1997).

Participants were selected by convenience at the workplace of the authors of this paper. The main objective was to find users ranging 25-50-year-old who were regular users of computers, Smartphones, applications and websites. The evaluation was done with a small user sample $(N=5)$. According to literature, this sample is enough to discover most of the usability problems (Lindgaard \& Chattratichart, 2007). However, is not enough to extract statistical conclusions nor to cover the whole spectrum of user diversity. Participants were 2 males and 3 females whose ages were between $30-35$ years $(M=31.6)$, and the Standard Deviation $(\mathrm{SD})$ was small $(S D=2.302)$. All the participants signed a consent form at the beginning of the evaluation session.

\subsection{Procedure}

The High-Fidelity prototype was used for the evaluation session. It started with a brief introduction where the purpose of the assessment was explained. The first objective of the session was to carry out 4 specific tasks with the digital interface applying 'Thinking aloud' methodology (Jääskeläinen, 2010) to extract the insights of the individuals. After ensuring the correct understanding of each task, we proceeded to start and record the start time and the completion time of proposed tasks. All the sessions were recorded. Whenever a user completed one task or the time limit expired, the task was tagged as finished and we proceed to the next one until completing the total. Then, some open questions were asked to the user about their opinion on the application, its usefulness and its degree of difficulty. Finally, each user filled out the ten item-based SUS questionnaires to measure the usability of the interface.

\subsection{Results}

The percentage of error in tasks-accomplishment is a quantitative data that indicates the usability errors of the system. The percentage of error of the 20 tasks (4 tasks per user that have been executed by 5 users in total) executed in the usability test was 0 . This is a positive 
IADIS International Journal on Computer Science and Information Systems

fact that triangulates accordingly to the other two tests: the SUS questionnaire and the qualitative data.

The main conclusion drawn from the semi-structured interview was that most of the ideas provided were positive related to the acceptance of the application. Only two ideas revealed negative aspects (confusion and difficulty of concrete elements of the interface). We argue, that proportion-wise the $92.3 \%$ of positive insights gives an overall satisfactory evaluation of the digital artefact. The SUS questionnaire is evaluated in a score range from 0 to 100 , where 0 is the lowest score and 100 the highest. The average score obtained among the 5 participants was $85,50(S D=4.808)$. As the data reveal, the score in all the questionnaires was above 80 , which is why the usability of the designed interface was validated (according to the creators of the instrument, a SUS score above a 68 would be considered above average).

\section{FINDINGS AND DISCUSSION}

After the evaluation of the application, the results were analysed, extracting the most relevant information of the data. The overall results were satisfactory and promising. The users had satisfactory involvement during the evaluation sessions, and their feelings and opinions about the system were positive. This conclusion is extracted taking into account the high involvement of users, the willingness to participate in future evaluation sessions and the general interest shown towards the application and its future development.

Next, the main aspects extracted from the development of the research, design and evaluation are detailed and discussed.

\subsection{The System was perceived as interesting}

From the initial research to the final evaluation the qualitative data reveals that the users perceived the system as useful and interesting for their everyday lives. The insights extracted from the users indicate that this application would be easily embraced in the workplace. Overall facilitating the understanding of the energy consumption and connecting with it, which is a major issue in work environments.

\subsection{The Application was evaluated as usable and Simple}

The usability of the system was validated through the instruments used in the evaluation phase. Zero-error rate at the usability test (task-accomplishment), high score of SUS questionnaire (much higher than the general average) and the qualitative data extracted from the semi-structured interviews established that the system is understandable and easy to use for the users. Simplicity seems to be a key factor to facilitate the understanding of messages and the management of energy processes of the devices. Plain text tags and the synthesis of visual communication enhances learnability and the effective use of the system, helping to get a positive UX. 


\subsection{The positive UX was paramount for users' engagement}

The data extracted from the evaluation shed lights on the potential UX and usability may have to generate positive impact towards forming more sustainable behaviour. Indeed, users seems to be more aware of the messages emitted through these this type of easy-to-use and personalised systems. The content was assessed as highly valuable, which might be also an indicative factor of the link between UX and positive perception of the energy awareness related content.

\subsection{Discussion}

As mentioned throughout this paper, UCD can help improving these systems by using UCD research methodologies. The results show a positive feedback of the system designed with UCD methodology. Although the development needs more iterations, we can state that the designed interface is based on the needs of the users and fits their mental models successfully.

The tools were focused on the evaluation of the usability and the UX of the digital interface. That give us the understanding of the relationship between the users with the system and of the legibility, learnability and comprehension of the interface. These aspects may help on the validation of the interface; however, we do still need to understand whether the messages and content provided by the interface are effective in changing users' attitude towards energy efficiency. Thus, making people more aware about sustainability issues and hence influencing pro-environmental behaviour change. Furthermore, the differences between the approximations of the literature pose a reflection on the categorization of users in which it is necessary to go in depth. The different dimensions reviewed need to be developed and implemented in flexible user profiles, including all types of people and addressing the phases of behaviour change. Besides, the reviewed user characterizations offer an approach based on a single dimension of the individual, like the behaviour or the values, missing other attributes of the user. To involve the complexity of the individual in an optimised profiling, different dimensions should be included. Thus, one possible approach could be a flexible characterization including different dimensions of the individual (behaviour, values, awareness...) and taking into account the phases of the behaviour change. This taxonomy should be linked with sustainable behaviour change strategies, selecting those offer a positive experience and feelings to promote the positive impact and to improve the acceptance of the message provided.

\section{CONCLUSIONS AND FUTURE WORK}

In this paper, a digital interface applying UCD methodologies was developed to increase user awareness on the need to enhance energy efficiency at work. The main contribution is that user diversity has been addressed in the interface proposed by adopting a mix of the strategies related to user classification based on the reviewed theoretical background. Besides, the system was evaluated with users through three different methods to extract knowledge about the impact of the UCD and UX on the user predisposition towards the usage of the proposed interface. The findings validated the usability of the system which puts in relevance the usefulness of the UCD as a methodology and the UX as a tool to engage the user towards 
IADIS International Journal on Computer Science and Information Systems

more conscious pro-environmental behaviour. Although the conclusions of the evaluation phase are satisfactory we need to take into account the limitations of the evaluation process. Thus, it is highly recommended to perform another usability test over time and with more users to expand the sample.

As highlighted in the previous sections, some studies explored the theoretical implications and the need of the UCD and the UX on the design of sustainable interfaces (Haines et al., 2015; Wever et al., 2008). However, to the best of our knowledge, most of the related works do not include a UCD methodology as a relevant technique of the sustainable interface design. Indeed, we have not been able to find scholars relating the impact of the UX on the energy awareness of the users. Therefore, we cannot calculate yet to what extent the UCD and the UX are effective on DfSB. To try to contribute to solve this, we developed a system that faces the diversity of users through the methodology DCU, offering a desirable UX.

The future research lines should aim to improve the proposed interface, developing prototypes in quick iterations. Besides, the design process must be complemented with continuous evaluations with users. In fact, the number of participants needs to be increased to statistically assess its potential to increase energy consumption awareness at workplace. Research-wise, we envisage the generation of flexible user profiles (i.e. adaptive profiles which can be slightly modified throughout time) based on behavioural theories. This will involve the understanding of all the stages of the pro-environmental behaviour in order to be able to adapt our digital interface to them. For that, we need to understand the we need to understand the different dimensions we already identified and develop characterisation standards.

\section{ACKNOWLEDGEMENT}

This work has been partially supported by the European Commission through the project HORIZON2020- RESEARCH \& INNOVATION ACTIONS (RIA) - 696129 GREENSOUL.

\section{REFERENCES}

Abras, C., Maloney-Krichmar, D., Preece, J. (2004). User- Centered Design. Work, 37(4), 445-456. https://doi.org/10.3233/WOR-2010-1109

Aoyama, M. (2007). Persona-Scenario-Goal Methodology for User-Centered Requirements Engineering. Proceedings - 15th IEEE International Requirements Engineering Conference, RE 2007, 307-312. https://doi.org/10.1109/RE.2007.50

Brooke, J. (1996). SUS - A quick and dirty usability scale. Usability Evaluation in Industry, 189(194), 4-7.

Casado-Mansilla, D. (2016). Promoting long term energy-efficient behaviour in work environments through persuasive technologies. University of Deusto, Bilbao, Spain. Retrieved from https://morelab.deusto.es/media/publications/theses/diego-casado-mansilla.pdf

Cor, E., \& Zwolinski, P. (2014). A procedure to define the best design intervention strategy on a product for a sustainable behavior of the user. Procedia CIRP, 15, 425-430. https://doi.org/10.1016/j.procir.2014.06.075

Corry, M., Frick, T. W., \& Hansen, L. (1997). User-centered Design and Usability Testing of a Web 
Site: An Illustrative Case Study. Educational Technology Research and Development, 45(4), 65-76. https://doi.org/10.1007/BF02299683

Coskun, A., Design, I., \& East, M. (2014). User diversity in design for behavior change Design for pro-environmental behavior change. Proceedings of DRS 2014, (JUNE 2014).

Haines, V., Mitchell, V., \& Ross, T. (2015). User Centred Design As An Enabler of Sustainable HCI, $1-4$.

Halko, S., \& Kientz, J. A. (2010). Personality and Persuasive Technology: An Exploratory Study on Health-Promoting Mobile Applications. Persuasive Technology, 6137(April 2017), 150-161. https://doi.org/10.1007/978-3-540-68504-3

Harley, A. (2015). Personas Make Users Memorable for Product Team Members. Retrieved from https://www.nngroup.com/articles/persona/

He, H., Greenberg, S., \& Huang, E. (2010). One size does not fit all: applying the transtheoretical model to energy feedback technology design. ... of the 28Th International Conference on ..., 927-936. https://doi.org/10.1145/1753326.1753464

Hedin, B., \& Zapico, J. (2017). Persuasive Technology: Development and Implementation of Personalized Technologies to Change Attitudes and Behaviors, 10171, 175-185. https://doi.org/10.1007/978-3-319-55134-0

Hekler, E. B., Klasnja, P., Froehlich, J. E., \& Buman, M. P. (2013). Mind the Theoretical Gap: Interpreting, Using, and Developing Behavioral Theory in HCI Research. Proc. CHI 2013, 3307-3316. https://doi.org/10.1145/2470654.2466452

Jääskeläinen, R. (2010). Think-aloud protocol. Handbook of Translation Studies, 1(371-373).

Kaptein, M., Lacroix, J., \& Saini, P. (2008). Individual Differences in Persuadability in the Health Promotion Domain. Persuasive Technology, 5033(March 2015), 1-12. https://doi.org/10.1007/9783-540-68504-3

Kitzinger, J. (1995). Qualitative research: Introducing focus groups. BMJ : British Medical Journal, 311(7000), 299-302. https://doi.org/10.1136/bmj.311.7000.299

Law, E. L.-C., Roto, V., Hassenzahl, M., Vermeeren, A. P. O. S., \& Kort, J. (2009). Understanding, scoping and defining user experience. Proceedings of the 27th International Conference on Human

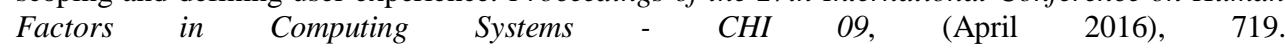
https://doi.org/10.1145/1518701.1518813

Lilley, D., Bailey, V., \& Charnley, F. (2013). Design for sustainable behaviour: a quick fix for slower consumption? Retrieved from https://dspace.lboro.ac.uk/dspace-jspui/handle/2134/12514

Lindgaard, G., \& Chattratichart, J. (2007). Usability testing: what have we overlooked? Proceedings of the SIGCHI Conference on Human Factors in Computing Systems - CHI '07, 1415-1424. https://doi.org/10.1145/1240624.1240839

Lockton, D., Harrison, D., \& Stanton, N. a. (2012). Models of the user: designers' perspectives on influencing sustainable behaviour. Journal of Design Research, 10(1/2), 7-27. https://doi.org/10.1504/JDR.2012.046137

Lockton, D., Harrison, D., \& Stanton, N. A. (2008). Making the user more efficient: design for sustainable behaviour. International Journal of Sustainable Engineering, 1(1), 3-8. https://doi.org/10.1080/19397030802131068

Mackay, W., \& Fayard, A.-L. (1997). HCL, Natural Science and Design: A Framework for Triangulation Across Disciplines. Proceedings of the 2nd Conference on Designing Interactive Systems: Processes, Practices, Methods, and Techniques, 223-234. https://doi.org/10.1145/263552.263612

Nielsen, J. (1994). Usability inspection methods. Conference Companion on Human Factors in Computing Systems - CHI '94, 25(1), 413-414. https://doi.org/10.1145/259963.260531

Petkov, P., Foth, M., Köbler, F., \& Krcmar, H. (2011). Motivating Domestic Energy Conservation through Comparative, Community-Based Feedback in Mobile and Social Media. 5th International Conference Energy \& Sustainability, (July), 21-30. https://doi.org/10.1145/2103354.2103358 
IADIS International Journal on Computer Science and Information Systems

Petkov, P., Goswami, S., Köbler, F., \& Krcmar, H. (2012). Personalised eco-feedback as a design technique for motivating energy saving behaviour at home. Proceedings of the 7 th Nordic Conference on Human-Computer Interaction Making Sense Through Design - NordiCHI '12, 587. https://doi.org/10.1145/2399016.2399106

Sax, H., Allegranzi, B., Uçkay, I., Larson, E., Boyce, J., \& Pittet, D. (2007). "My five moments for hand hygiene": a user-centred design approach to understand, train, monitor and report hand hygiene. Journal of Hospital Infection, 67(1), 9-21. https://doi.org/10.1016/j.jhin.2007.06.004

Vredenburg, K., Mao, J.-Y., Smith, P. W., \& Carey, T. (2002). A survey of user-centered design practice. Proceedings of the SIGCHI Conference on Human Factors in Computing Systems Changing Our World, Changing Ourselves - CHI '02, (1), 471. https://doi.org/10.1145/503457.503460

Wever, R., van Kuijk, J., \& Boks, C. (2008). User Centered Design for Sustainable Behaviour International Journal of Sustainable Engineering, 1(September), 9-20. https://doi.org/10.1080/19397030802166205

Whiting, L. S. (2008). Semi-structured interviews: guidance for novice researchers. Nursing Standard, $22(23), 35-40$.

Wood, JR; Wood, L. (2008). Card sorting: current practices and beyond. Journal of Usability Studies.

Yun, R., Aziz, A., Lasternas, B., Loftness, V., Scupelli, P., \& Zhang, C. (2017). The persistent effectiveness of online feedback and controls for sustainability in the workplace. Energy Efficiency. https://doi.org/10.1007/s12053-017-9509-4 